\title{
How Feature- and Communication Constraints in CSS Affect Creative Collaboration in Virtual Teams - An Activity Theory Perspective
}

\author{
Raoul Pilcicki \\ Jacobs University Bremen \\ r.pilcicki@jacobs-university.de
}

\author{
Dominik Siemon \\ LUT University \\ dominik.siemon@lut.fi
}

\author{
Christoph Lattemann \\ Jacobs University Bremen \\ c.lattemann@jacobs-university.de
}

\begin{abstract}
New Creativity Support Systems (CSS) provide additional features, but are also growing more complex and difficult to operate. Via new functionalities, CSS aim to facilitate virtual creative collaboration and enable better outcomes. However, research shows that, especially in the context of creativity, better outcomes are not always the result of more options and features. Our study applies activity theory (AT) as a lens in order to examine how constraints can be applied to creative collaboration in virtual teams. This study advances research on collaboration in information systems (IS) as well as human-centered development of IT-artifacts that facilitate creative collaboration. Our findings provide two practical takeaways for CSS developers and virtual teams: First, constraints in CSS can be designed to substantially benefit idea generation and exploration beyond routine performance; second, constraints can be designed to help teams access the potential of CSS faster and more efficiently.
\end{abstract}

\section{Introduction}

In a world that continues to become increasingly connected, with shorter product life cycles as well as extensive digitization and the resulting influence of customers, the requirements for companies to survive in the market are growing [1]. Global crises such as the COVID-19 pandemic present companies with further challenges that affect their day-to-day working practices [2]. In return, digitalization offers potentials for organizational transformation and shared virtual value creation [3]. In this environment, innovations take on a special role, enabling companies to secure sustainable business success. Innovations arise primarily through joint and, above all, creative work in which multidisciplinary teams tackle complex problems and come up with novel and effective ideas [4]. Not only triggered by the COVID-19 pandemic, but already with the upswing in information technology (IT), companies are relying on virtual teams and digital collaboration for joint value creation $[5,6]$. This increased need for decentralized collaboration drives the development of nextgeneration Creativity Support Systems (CSS) that enable virtual teams and individuals to promote creativity and collaboration in new ways $[7,8,9,10]$. CSS are used specifically to support the creative work of individuals or teams and to develop new ideas that are considered the cornerstone for future innovations that are successful in the market. CSS can therefore be described as a subcategory of collaboration support systems, that provide specific support for creative processes and the generation of ideas. A wide range of capabilities for interaction, knowledge sharing or innovative collaboration processes is implemented into these CSS $[11,12,13]$, which are supposed to lower activation costs and provide users with a larger vocabulary of actions [14]. However, these capabilities can exceed the optimal level, cause feature fatigue or confusion and thus become serious obstacles for successful creative collaboration $[15,16]$.

Previous research suggests an inverted-Urelationship between creative collaboration and constraints and proposes that limited availabilities of tools, functionalities or interactions can cause individuals to be more engaged in their creative activities $[17,18,19]$. To our understanding, the design and implementation of constraints in virtual contexts to effectively support creative collaboration across disciplines is still under-researched. Our research therefore examines the following question:

How do constraints in CSS affect creative collaboration in virtual teams?

To examine the relationship between constraints and creativity in virtual collaboration, we conducted an exploratory study with 46 participants of a virtual Design Thinking (DT)-workshop. Our experiment manipulated whether the participants were exposed to feature constraints or not and communication constraints or not in a 2x2 study design. Applying an Activity Theory perspective, we analyze how these 
constraints can affect creative collaboration in CSS by studying tensions, focus shifts and transformations in creative collaboration under these different constraintconditions [20].

\section{IT-supported Creativity}

As a part of socio-technical systems (Information Systems, or IS), IT can enable groups and individuals to perform certain tasks. IS consist of humans, tasks and technologies (hardware and software) that produce, distribute and process data or information [21]. CSS are IS that support creativity and aim to stimulate creativity-related processes on an individual or collective level $[7,9]$. Their goal is to facilitate and document creative processes in order to support creativity. Information exchange, idea comparison and synchronous communication in CSS are supposed to provide participants with cognitive or social stimulation [7, 22, 23]. The design of CSS can be focused on supporting different individual or group creativity processes. Different features and functionalities support different creative processes. Voigt and Bergener [24], for example, have proposed an integrated framework that identifies 13 design principles focused on CSS. Among other things, they mention the need for rich communication and describe a number of features, such as a shared idea space, that are used to support creative work. Müller-Wienbergen et al. [8] also show in their work how certain features can be used to support convergent and divergent thinking in particular. Besides certain features, the possibility of communication and its richness in CSS also plays a crucial role, as communication is important to ensure shared mental models, which are considered fundamental for successful creative collaboration in teams [25]. Hence, via multichannelcommunication (e.g. communication in forums and simultaneous connection of team members via phone, video-chat, etc.), virtual teams are to be enabled in their creative activities [26]. CSS can be described as webs of mediators which enable users to perform actions that lead towards achieving their objectives or goals $[16,20]$. To do so, CSS do not always need to offer more features, but also limit what functionalities are available to users $[20,27,28]$.

\section{Creativity under Constraints}

Constraints in the context of creativity can be defined as "explicit or tacit factors governing what the creative agents must, should, can, and cannot do and what the creative output must, should, can, and cannot be" [28, p. 9]. They can be inherent in materials, tools, contexts or situations, imposed by external agents or voluntarily self-imposed [29]. Reason suggests that constraints limit autonomy and control over decisions or procedures and therefore should be reduced when supporting creativity $[30,31]$. However, research shows that constraints can stimulate creativity by causing teams to become more adaptive and efficient $[19,32]$, channel cognitive resources [33] and decrease the need for information processing [34, 35]. For instance, constraints can promote surprising responses to complex problems while simultaneously precluding predictable ones [36]. Absence of constraints can even demotivate individuals and cause them to take „the path of least resistance“, coming up with familiar and easy-to-generate ideas [32, 37].

Regarding their occurrence in creative processes, constraints can be distinguished between inputconstraints (,Unavailability of resources and materials that could be used in the service of creativity and innovation activities"'), process-constraints (,Restrictions that determine the steps to be followed throughout innovation and creativity processes") and output-constraints (,Factors that define the end result of the creative processes, such as the constraints on what the output should or should not contain and/or achieve“) [38, p. 99]. Via motivational, cognitive and social mechanisms, teams can turn constraints into creative outcomes, new ideas and innovative solutions [38].

Modern frameworks for creative collaboration like Design Thinking (DT) guide teams through phases of high openness (called diverging) and phases of focused analysis and critical idea selection (called converging) in order to analyze problems and develop new solutions in an iterative way [39]. In DT, following a phase of divergent exploration of a given problem, insights are synthesized in a convergent phase, which forms the basis for another exploratory, divergent phase to generate various potential solutions $[39,40]$. In a final phase, those solutions are first carefully analyzed and filtered, then refined and tested in a further converging phase [41]. Due to their apparently limiting character, constraints seem to be mainly relevant in analytical work phases (convergence), but previous research suggests that constraints can also support phases of exploratory idea search (divergence) [42, 43]. However, the strategic application of constraints has been suggested to help DT practitioners overcome cognitive obstacles which keep them from generating novel and useful ideas [44]. 


\section{Activity Theory}

It is crucial to recognize that humans act via technology rather than merely interact with it when studying creative collaboration in CSS [16]. This relevance of social and developmental aspects of CSS usage is emphasized by Activity Theory (AT) $[45,46]$. AT offers a robust framework for research and design explorations, as well as a greater understanding of the role of technical artifacts in daily life [47]. AT can be used to study how an artifact affects collaboration and how collaboration potentially affects the use of the artifact [27].

In AT, a distinction is made between temporary, goal-directed actions and long-term, object-oriented activity systems $[48,49,50]$. Activity results from tensions and instability as well as the development of new needs in the activity system. According to AT, users do not merely react to opportunities in the collaborative environment, but constantly recreate that environment through activity [27]. In activity systems, subjects divide labor, adapt towards their tools and reproduce tool-knowledge in their community [46, 51]. Creativity in activity therefore can be described as a form of development which is based on the continuous arising and resolving of tensions within the system during activities [45].

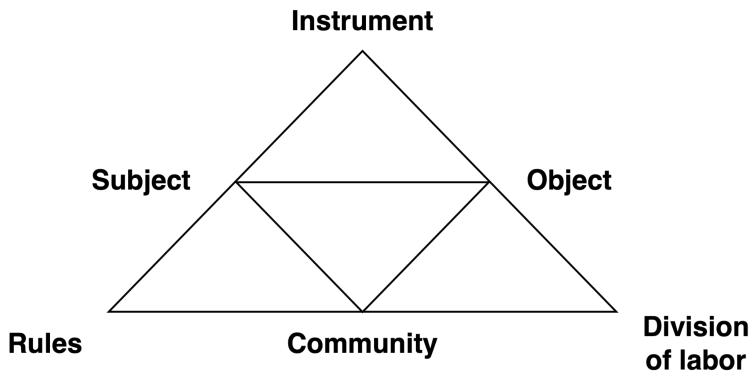

Figure 1. System of collective activity, according to Engeström [50].

According to AT, activity emerges from a set of six elements, which are interdependent and represent different facets of the whole activity [46, 49, 50]:

(1) Instruments - external and internal mediating artifacts, used to complete a task, 2) Subject - an individual or group of people participating in activities, (3) Object - the overarching objective of the activity system, (4) Community - the participants and their social context, (5) Division of labor - the activity system's balance of activity among different people and artifacts, (6) Rules - the system's rules and code for behavior and actions. Figure 1 depicts a system of collective activity based on these elements.

\section{Method}

To study how constraints in CSS potentially affect creative collaboration in virtual teams, we conducted an exploratory series of experiments in which four different conditions were tested [52]. We chose a between-subject design in which 46 participants (20 male, 24 female, two preferred not to say) between 17 and 37 years old (mean=22) from diverse undergraduate programs such as Industrial Engineering, International Business Administration and Psychology were divided into multidisciplinary teams collaborating on a given task with a given CSS. The process was embedded in a 90-minute DTworkshop setting with the goal to collaborate and generate both original and applicable solutions for a given task. DT is a method that enables teams to solve people-centered problems in innovative ways [53, 54], which can be performed virtually $[55,56]$. The system we used was a digital whiteboard which has been proven as a reliable tool to conduct virtual DTworkshops [25,57]. The participants were given a case scenario with the task to exploratorily generate various ideas to a given problem (Advising universities on how to facilitate social interactions on and off campus in times of social distancing during the COVID-19 pandemic) and then synthesize and select the three most original and feasible ideas. The task involved both divergent and convergent collaboration, as constraints can have different effects on those phases in a creativity process $[42,43]$. The task was designed to allow multidisciplinary contributions without any special knowledge from the participants. The participants had 30 minutes to jointly work on the given task, independently coordinate their actions and create an innovative solution.

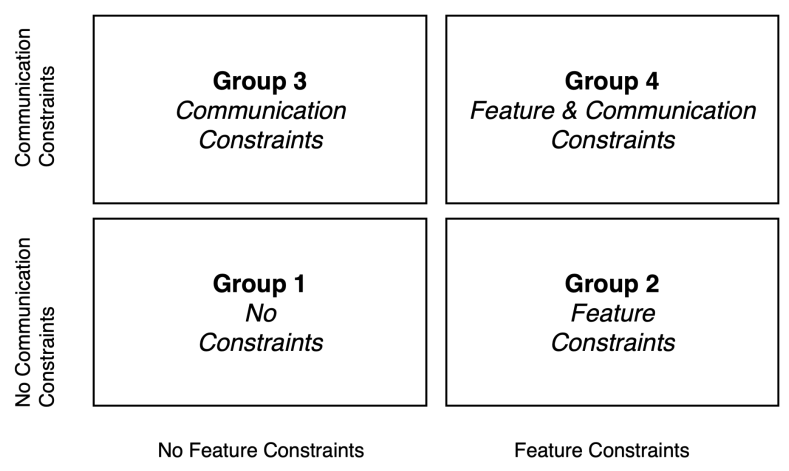

Figure 2. Experimental design based on four conditions of constraints.

Based on a $2 \times 2$ study design, participants collaborated either under no constraints (Group 1), 
feature constraints (Group 2), communication constraints (Group 3) or both feature and communication constraints (Group 4), as illustrated in Figure 2. Within each group, participants were randomly allocated to teams of similar sizes (4-7 people per team, which can enable teams following agile methods like DT to perform at peak efficiency [58]). Due to technical difficulties, one team from group 2 had to be integrated into the other groups, which resulted in three teams for group $1(n=12)$, one team for group $2(n=4), 3$ teams for group $3(n=15)$ and three teams for group $4(n=15)$. The participants were not informed about possible constraints of the CSS. We chose communicative constraints for the purpose of our study (no synchronous communication, videoconferencing or phone calls during the exercise), as constraints to interactions, communication and information sharing can have a positive effect on creative collaboration $[38,59]$, generation of ideas $[60,61]$ and mitigation of social barriers to knowledge exchange [61, 62]. We chose feature constraints (no features allowed except the most basic yellow sticky notes during the exercise) because limited availabilities of tools or functionalities can make virtual environments easier to work in [28, 63], and motivate experimentation and risk-taking in the creative process $[17,64]$.

Prior to the beginning of the experiment, all participants took part in an introductory session in which the theory and method of DT were explained and a test exercise was performed on the digital whiteboard to ensure sufficient skill levels of all participants. During the experiment, each group was followed by one neutral investigator observing the dynamics on the whiteboard. All team activities on the whiteboards were screen-recorded for further analysis. After the experiment, participants filled out a short survey on their experience of constraints in the experiment, the effect of those constraints on their individual and collective performance as well as coping mechanisms to handle those constraints. The collected data was analyzed, coded and abstracted according to Mayring's qualitative content analysis [65], using an inductive/deductive combinational approach to extract patterns and counterparts from the subjects' statements. The goal was to identify relevant tensions in the division of labor as well as focus shifts or transformations of objects in the different teams. These concepts were deductively used as codes at the beginning. During the analysis, new codes were inductively created and refined within several iterations. Two or more coders tested the validity of the initial coding process, following the methodological implications of AT $[27,66]$.

\section{Results}

Understanding the elements of an activity system is the foundation for analysis in accordance with AT. Table 1 presents a high-level overview of the elements of each experimental group. All groups can be described as activity systems with a shared object of activity (generation of ideas and selection of the three most original and feasible ideas for the given problem), shared rules (independent coordination and joint work for 30 minutes) and multidisciplinarity of participants.

Table 1. Experimental groups
described as activity systems.

\begin{tabular}{|l|l|}
\hline \multicolumn{2}{|l|}{$\begin{array}{l}\text { Object: Idea generation and -selection } \\
\text { Subject: Multidisciplinary teams of 4-7 } \\
\text { Community: Workshop on DT with 46 participants } \\
\text { Rules: } 30 \text { min., self- coordination, joint work }\end{array}$} \\
\hline $\begin{array}{l}\text { Group 3 (n=15; 3 teams) } \\
\text { Instruments: Chat only + } \\
\text { All Features (Mural Board) }\end{array}$ & $\begin{array}{l}\text { Group 4 (n=15; 3 teams) } \\
\text { Instruments: Chat only, } 1 \\
\text { Color Sticky Notes only } \\
\text { (Mural Board) }\end{array}$ \\
\hline $\begin{array}{l}\text { Group 1 (n=12; 3 teams) } \\
\text { Instruments: All Channels } \\
+ \text { All Features (MS Teams, } \\
\text { Mural Board) }\end{array}$ & $\begin{array}{l}\text { Group 2 (n=4; 1 team) } \\
\text { Instruments: All Channels } \\
+1 \text { Color Sticky Notes } \\
\text { only (MS Teams, Mural } \\
\text { Board) }\end{array}$ \\
\hline
\end{tabular}

\subsection{Division of Labor}

As all teams had to coordinate independently, one central observation was the emergence of leadership and proactivity in the teams. Groups 1 and 2 showed little activity until mostly one participant started to actively work with the whiteboard, while in groups 3 and 4, board activity emerged fast at the beginning of the exercise and was more distributed among all team members. In teams working under communication constraints (group 3 and 4), participants felt motivated to take on leading roles ("It motivated my desire to take leadership given that none of my team members would. I think this team would have not been successful if no one decides to take leadership over the task.").

All participants reported varying levels of contributions in their teams. While groups 3 and 4 showed high levels of proactivity, involving general suggestions ("Feel free to add!"), self-reports ("Topic DONE!"), short comments and facilitating questions ("That sounds good!"; "Any more ideas on how to...?"), especially participants who felt motivated to take leadership in teams from these groups reported a 
lack of verbal communication ("You need more verbal communication to hold everybody accountable for their work, define goals, and discuss more."). Teams from group 1 on the other hand reported imbalances in verbal communication ("Some people were able to communicate and speak more than others").

\subsection{Tensions, Shifts and Mediations}

Groups working under constraints showed substantially different behavior than groups working without constraints. One central issue in group 1 were difficulties to coordinate channels for interaction at the beginning ("Join the call!"). These upfront efforts caused additional stress due to the limited time given. For instance, after being used for coordination, one team from group 1 cleaned the whiteboard again to then begin working on its task. Another central issue reported in these teams was an imbalance between talking and idea capturing ("Less talk, more ideas"). Participants stated that a stronger personal connection with others in the team would have helped collaborate ("Personal connection before the task") and reported criticality of audio quality for reception in the virtual collaboration.

Another tension was stress and information overload, reported by teams from group 3 ("It was dynamic and fun, but at some point also stressful due to misunderstandings"; "My concentration dropped after some time - too many stimuli."). Compared to that, while participants from group 1 did not report stress or overload, but showed substantially less overall activity and exploration in the board.

A central tension in group 3 was the participants' difficulty to react to or get the attention of their team or specific members ("I couldn't react fast enough"). Different ways of highlighting ideas or messages could be observed, such as drawing, handwriting or scaling of sticky notes, which intensified over time. Two issues reported from those teams were a lack of traceability ("Had to scale my sticky notes, but had trouble finding them back") and a lack of replies by other teammates ("They never replied to my comments"). Similar issues could be observed in teams from group 4. While they showed little difficulty with exploratory idea generation (a divergent phase in creative work), teams from group 4 showed noticeable difficulties to coordinate their collaborative transition into idea selection (a "convergent" phase in creative work). For instance, in one team, some participants were still generating ideas when others had already proceeded towards idea selection ("Have we found all ideas?" - "Let us not waste time and go ahead"). Some participants from group 4 reported strong levels of frustration due to a lack of verbal communication ("I felt quite frustrated because of not being able to talk my teammates") and felt blocked ("I felt blocked about raising ideas/solutions").

\subsection{Creative Collaboration}

The tensions and focus shifts that have been identified in step two provide a way for empirical investigation on how creative collaboration revealed itself under constraints. The most substantial difference between the teams was observed with regard to idea exploration and idea selection. Teams that worked without any constraints (group 1) generated fewer ideas and showed substantially less exploration of those ideas. In one case, a team narrowed its focus to a sub-aspect of the given question and quickly generated first solutions in the first third of the exercise, then spent the remaining time moving and rearranging those ideas. Its final idea selection was a mild variation of those very first ideas, with little change or exploration in the process, as notes were copied, including all details. While participants did not contribute equally to the process, teams that worked without constraints perceived their collaborative performance positively ("We worked really good as a group."; "Some people contributed more than others but this is the case in every task."). Teams from group 2 showed most activity during idea generation in the beginning of the experiment, which slowed down substantially after the first third of the exercise. Following the provided structure, participants managed to select ideas towards the end but showed little exploration in the process.

Another central observation consistent across those teams from group 1 that worked without constraints is the emergence of a very distinct logical structure for information on the whiteboard. The teams showed the least use of features (sticky note with bullet points and arrow as connector) and did not make use of the basic structure provided for the exercise. For instance, final ideas were not collected in the respective section of the whiteboard but marked in the facilitator's own mindmap (see Figure 3). 

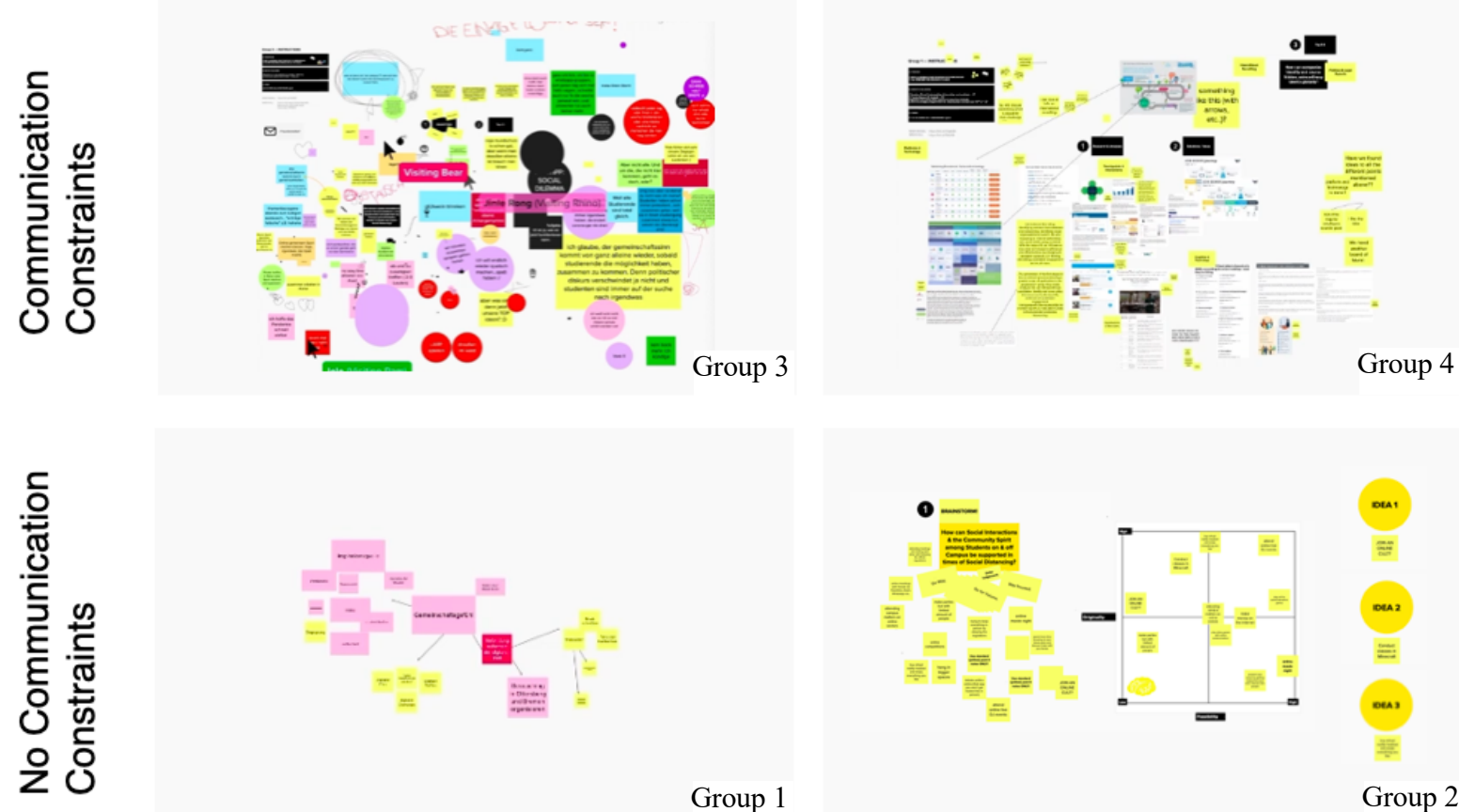

Group 1

No Feature Constraints

Feature Constraints

Figure 3. Idea generation and feature use under four conditions.

The largest variety of ideas and sub-aspects was generated by teams from group 4. Exploratory idea generation started immediately after the beginning of the exercise and lasted until the last third of the exercise. Teams used the entire workspace available (i.e., the area of the digital whiteboard), which had to be expanded to continue in one case. Similar dynamics of fast and intense exploration could be observed in group 3. While most teams from group 4 used little to no features except sticky notes, one team worked around its feature constraints and started complementing yellow sticky notes with additional graphics.

Towards the second half of the exercise, teams from group 3 showed conflicting ideas about whether to focus on further exploration or shared understanding and idea selection ("But what are our top 3 ideas?"), hence struggling to coordinate and finish with a convergent selection of ideas ("Our assignment was not completed effectively"). Teams from group 4 showed similar difficulty to converge and synthesize towards the end of the exercise. While every team was able to present a final selection of ideas, participants reported a lack of mutual decisionmaking ("Our final idea selection was not a joint decision. I don't even know what was selected").

\section{Discussion and Conclusion}

In this paper, the AT framework was applied to identify tensions and transformative potential of constraints in the context of virtual, creative collaboration in CSS. For the purpose of the research, an exploratory series of experiments on divergent idea generation and convergent idea selection under communication and feature constraints were carried out. The study first reviewed the known effects constraints can have on creative collaboration based on the literature and then introduced AT as a framework for identifying potential tensions, focus shifts and mediations between the elements of activity systems. The potential tensions and focus shifts within the groups' activity system were then identified through the lens of AT. Each identified tension can be studied regarding its contribution to the creative collaboration.

Previous researchers have suggested that CSS should provide more functionalities and capabilities in order to specifically support creative collaboration in virtual teams [9, 10, 24]. However, our findings suggest that more capabilities in CSS do not always yield better results. 
A key finding (see Table 2) from our study is that teams that could use all features of a CSS and were unconstrained in their communication (group 1) used the least features and generated the least ideas (see Figure 3). One possible explanation for this apparently paradox effect is that teams do not always choose those means that are best suited to perform a task and resolve collaborative tensions, but those that are most familiar or easiest to use for the emerging facilitators in those teams, hence running in danger of taking the path of least resistance and generating solutions that are less original or applicable [32, 37]. As previous research proposed [36, 38], our study showed that individuals and teams collaborating under constraints can generate more creative solutions .

Creative collaboration in CSS can enable "almost immediate" pickup of information about possibilities offered by the collaborative environment [46]. We found that for some participants, limited means to communicate and react to other team members in real time can increase stress or information overload during idea exploration and negatively impact their motivation to further engage in creative collaboration. One possible explanation is that communication constraints in CSS can cause participants to perceive a loss of control and influence during the collaboration $[30,31]$. However, our experiment has also shown that constraints in CSS can substantially benefit the exploratory generation of variety and ideas and facilitate the emergence of stimuli as sources for inspiration rather than limit them, as previous research on CSS suggested [10].

We propose that constraints in CSS can help promote more radical forms of creativity and motivate risk-taking by limiting the presence and availability of coworkers in exploratory phases of creative collaboration, as these can contribute to incremental creativity, conformity and routine performance [67].

Table 2. Key observations based on AT

\begin{tabular}{|l|c|c|c|}
\hline & $\begin{array}{c}\text { Division of } \\
\text { Labor }\end{array}$ & $\begin{array}{c}\text { Tensions I } \\
\text { Difficulties }\end{array}$ & $\begin{array}{c}\text { Creative } \\
\text { Collaboration }\end{array}$ \\
\hline Group 1 & $\begin{array}{c}\text { Continuous } \\
\text { Facilitation }\end{array}$ & $\begin{array}{c}\text { "More Talk, } \\
\text { less Ideas" }\end{array}$ & $\begin{array}{c}\text {-- Divergence } \\
\text { + Convergence }\end{array}$ \\
\hline Group 2 & $\begin{array}{c}\text { Occasional } \\
\text { Facilitation }\end{array}$ & $\begin{array}{c}\text { "Path of Least } \\
\text { Resistance" }\end{array}$ & $\begin{array}{c}\text {-- Divergence } \\
\text { + Convergence }\end{array}$ \\
\hline Group 3 & $\begin{array}{c}\text { Distribution } \\
\text { vs. Leadership }\end{array}$ & $\begin{array}{c}\text { Information } \\
\text { Overload }\end{array}$ & $\begin{array}{c}\text { + Divergence } \\
\text {-- Convergence }\end{array}$ \\
\hline Group 4 & $\begin{array}{c}\text { Distribution } \\
\text { \& Proactivity }\end{array}$ & $\begin{array}{c}\text { Lack of } \\
\text { Coordination }\end{array}$ & $\begin{array}{c}\text { ++ Divergence } \\
\text {-- Convergence }\end{array}$ \\
\hline
\end{tabular}

During our experiment, teams relied on both social as well as technological means to collaborate creatively, which supports the concept in AT that mediation in activity systems emerges from the simultaneous interplay of various system elements $[45,46]$. Hence, as technology-based collaboration involves learning of that technology, we reason that constraints can enable users to perform those actions that help them access the technology's instrumental potential and complete their goals [20, 27, 46]. For instance, as teams that worked under additional feature constraints reported less overload, we reason that communication and feature constraints in CSS can function both as restrainers and enablers $[17,18,36]$, which can be balanced in a way that contributes to an optimal level of constrainedness without causing stress or overload for participants [18].

In this study, teams that worked without any constraints showed a distinct, emergent logical structure for their ideas, which might be an indicator for shared team knowledge [25], as in a previous study, teams that were unconstrained in their communication showed significantly higher levels of shared knowledge than teams that worked under communication constraints [68]. However, while shared mental models are related to low levels of intragroup conflict and high levels of team satisfaction [69], we support the argument that gaps in shared understanding can be a reasonable trade-off in order to maintain rapid feedback learning cycles when solving complex problems [70].

While teams working under communication constraints performed well in the divergent, exploratory phase of the task, they showed difficulty in moments of ad hoc coordination and during convergent idea selection. We therefore argue that successful mediation of tensions during creative collaboration in CSS requires appropriate capabilities for shared communication [20,27,46], but propose that these capabilities do not necessarily need to be available throughout the entire process. Further research is required to study how the intensity and combinations of constraints in a CSS can be manipulated over time in order to maintain that balance throughout the phases of creative collaboration.

However, our paper also comes with a number of limitations that require further research. The small number of participants and consequently few teams, especially in group 2, do not allow generalization of the results. Thus, the number of participants should be increased in order to be able to compensate for moderator effects such as the individual strengths, working methods or preferences of the participants. In addition, future studies should rely on a more diverse and representative subject group with different levels of professional experience, as we had mainly young, 
IT-savvy students as participants. In the course of this, the context of the task and the task itself have to be varied, since it was very much tailored to our group of participants. A different task, with which the participants might not be so familiar, could have led to different results. Another limiting aspect is the time it took participants to become familiar with the system. In particular, teams working without constraints might have needed longer to get familiar with all features. Experienced users would not have this familiarization phase with the system and could start directly and know which features they can and want to use.

Finally, the following likely transferable learnings were identified: First, limited functionalities and means of communication can be strategically designed and implemented into CSS in a way that helps teams mitigate the learning and application of a technology for creative collaboration and hence prevent confusion $[16,27,36,46]$. Second, limited functionalities and means of communication can facilitate the emergence of inspirational stimuli in CSS and help users access the instrumental potential of CSS $[20,27,28,46]$. By limiting the presence and availability of coworkers in exploratory phases of creative collaboration, constraints in CSS can substantially benefit the generation and exploration of ideas beyond routine performance and thus promote more radical forms of creativity [36, 67]. Third, while we found that successful creative collaboration in CSS requires means for shared communication in order to enable coordination and avoid information overload [20, 27, 46], we suggest that those capabilities do not need to be available throughout the entire process, especially when collaborating creatively in rapid feedback cycles [67].

\section{References}

[1] Anning-Dorson, T., "Innovation and competitive advantage creation", International Marketing Review, 2018.

[2] Azoulay, P., and B. Jones, "Beat COVID-19 through innovation”, Science 368(6491), 2020, pp. 553-553.

[3] Wessel, L., A. Baiyere, R. Ologeanu-Taddei, J. Cha, and T. Blegind-Jensen, "Unpacking the difference between digital transformation and IT-enabled organizational transformation", Journal of the Association for Information Systems 22(1), 2021.

[4] DiLiello, T.C., and J.D. Houghton, "Creative potential and practised creativity: Identifying untapped creativity in organizations", Creativity and Innovation Management 17(1), 2008, pp. 37-46.

[5] Alavi, M., and A. Tiwana, "Knowledge integration in virtual teams: The potential role of KMS", Journal of the
American Society for Information Science and Technology 53(12), 2002, pp. 1029-1037.

[6] Driskell, J.E., P.H. Radtke, and E. Salas, "Virtual Teams: Effects of Technological Mediation on Team Performance", Group Dynamics: Theory, Research, and Practice 7(4), 2003, pp. 297-323.

[7] Shneiderman, B., "Creativity Support Tools: Accelerating Discovery and Innovation", Commun. ACM 50(12), 2007, pp. 20-32.

[8] Müller-Wienbergen, F., O. Müller, S. Seidel, and J. Becker, "Leaving the Beaten Tracks in Creative Work - A Design Theory for Systems that Support Convergent and Divergent Thinking", Journal of the Association for Information Systems 12(11), 2011.

[9] Gabriel, A., D. Monticolo, M. Camargo, and M. Bourgault, "Creativity support systems: A systematic mapping study", Thinking Skills and Creativity 21, 2016, pp. 109-122.

[10] Wang, K., and J.V. Nickerson, “A literature review on individual creativity support systems", Computers in Human Behavior 74, 2017, pp. 139-151.

[11] Fiol, C.M., and E.J. O'Connor, "Identification in Faceto-Face, Hybrid, and Pure Virtual Teams: Untangling the Contradictions", Organization Science 16(1), 2005, pp. 1932.

[12] Dulebohn, J.H., and J.E. Hoch, "Virtual teams in organizations", Human Resource Management Review 27(4), 2017, pp. 569-574.

[13] Lee, K.C., "Digital creativity: New frontier for research and practice", Computers in Human Behavior 42, 2015, pp. 1-4.

[14] Beaudouin-Lafon, M., "Instrumental interaction: an interaction model for designing post-WIMP user interfaces", Proceedings of the SIGCHI conference on Human Factors in Computing Systems, Association for Computing Machinery (2000), 446-453.

[15] Thompson, D.V., R.W. Hamilton, and R.T. Rust, "Feature Fatigue: When Product Capabilities Become Too Much of a Good Thing", Journal of Marketing Research 42(4), 2005, pp. 431-442.

[16] Kaptelinin, V., and B. Nardi, “Affordances in HCI: toward a mediated action perspective", Proceedings of the 2012 ACM annual conference on Human Factors in Computing Systems - CHI '12, ACM Press (2012), 967.

[17] Baer, M., and G.R. Oldham, "The Curvilinear Relation Between Experienced Creative Time Pressure and Creativity: Moderating Effects of Openness to Experience and Support for Creativity", The Journal of applied psychology, 2006.

[18] Onarheim, B., and M.M. Biskjaer, "Balancing Constraints and the Sweet Spot as Coming Topics for Creativity Research", Ball, L. (Ed.). Creativity in design. Understanding, capturing, supporting., 2017. 
[19] Rosso, B., "Creativity and Constraints: Exploring the Role of Constraints in the Creative Processes of Research and Development Teams", Organization Studies 35, 2014, pp. 551-585.

[20] Bødker, S., "Through the Interface - a Human Activity Approach to User Interface Design”, DAIMI Report Series(224), 1987.

[21] Heinrich, L.J., A. Heinzl, and R. Riedl, Wirtschaftsinformatik: Einführung und Grundlegung, Springer-Verlag, Berlin Heidelberg, 2011.

[22] Massetti, B., "An Empirical Examination of the Value of Creativity Support Systems on Idea Generation", MIS Quarterly 20(1), 1996, pp. 83-97.

[23] Siemon, D., and S. Robra-Bissantz, "A Creativity Support Tool for Cognitive Idea Stimulation in Entrepreneurial Activities", International Journal of Entrepreneurship and Small Business forthcoming, 2018.

[24] Voigt, M., and K. Bergener, "Enhancing Creativity in Groups - Proposition of an Integrated Framework for Designing Group Creativity Support Systems", 2013 46th Hawaii International Conference on System Sciences (HICSS), (2013), 225-234.

[25] Redlich, B., D. Siemon, C. Lattemann, and S. RobraBissantz, "Shared Mental Models in Creative Virtual Teamwork", Proceedings of the 50th Hawaii International Conference on System Sciences, (2017).

[26] Schouten, A.P., B. van den Hooff, and F. Feldberg, "Virtual Team Work: Group Decision Making in 3D Virtual Environments", Communication Research, 2013, pp. 0093650213509667.

[27] Bertelsen, O., and S. Bødker, Activity Theory, 2003.

[28] Bowman, D.A., and L.F. Hodges, User Interface Constraints for Immersive Virtual Environment Applications, Georgia Institute of Technology, 1995.

[29] Elster, J., Ulysses Unbound: Studies in Rationality, Precommitment, and Constraints, Cambridge University Press, 2000.

[30] Amabile, T.M., S.G. Barsade, J.S. Mueller, and B.M. Staw, "Affect and Creativity at Work", Administrative Science Quarterly 50(3), 2005, pp. 367-403.

[31] Amabile, T.M., and M.G. Pratt, "The dynamic componential model of creativity and innovation in organizations: Making progress, making meaning", Research in Organizational Behavior 36, 2016, pp. 157183.

[32] Finke, R.A., T.B. Ward, and S.M. Smith, Creative Cognition: Theory, Research, and Applications, A Bradford Book, Cambridge, Mass., 1996.

[33] Roskes, M., "Constraints that Help or Hinder Creative Performance: A Motivational Approach: Constraints That Help or Hinder Creative Performance", Creativity and Innovation Management 24(2), 2015, pp. 197-206.
[34] Simon, H.A., "A Behavioral Model of Rational Choice", The Quarterly Journal of Economics 69(1), 1955, pp. 99-118.

[35] Branscombe, N.R., and B.M. Cohen, "Motivation and complexity levels as determinants of heuristic use in social judgment", In Emotion and social judgments. Pergamon Press, Elmsford, NY, US, 1991, 145-160.

[36] Stokes, P.D., "Using constraints to create novelty: A case study.", Psychology of Aesthetics, Creativity, and the Arts 3(3), 2009, pp. 174-180.

[37] Hirst, G., D. Van Knippenberg, C. Chen, and C.A. Sacramento, "How Does Bureaucracy Impact Individual Creativity? A Cross-Level Investigation of Team Contextual Influences on Goal Orientation-Creativity Relationships", Academy of Management Journal 54(3), 2011, pp. 624-641.

[38] Acar, O.A., M. Tarakci, and D. van Knippenberg, "Creativity and Innovation Under Constraints: A CrossDisciplinary Integrative Review", Journal of Management 45, 2019, pp. 96-121.

[39] Brenner, W., F. Uebernickel, and T. Abrell, "Design Thinking as Mindset, Process, and Toolbox", In Design Thinking for Innovation. Springer, Cham, 2016, 3-21.

[40] Redlich, B., F. Becker, S. Fischer, et al., "Das DETHIS-Verfahren", In V. Stich, J.H. Schumann, D. Beverungen, G. Gudergan and P. Jussen, eds., Digitale Dienstleistungsinnovationen: Smart Services agil und kundenorientiert entwickeln. Springer, Berlin, Heidelberg, 2019, 73-88.

[41] Lindberg, T., C. Meinel, and R. Wagner, "Design Thinking: A Fruitful Concept for IT Development?", In C. Meinel, L. Leifer and H. Plattner, eds., Design Thinking. Springer Berlin Heidelberg, 2011, 3-18.

[42] Biskjaer, M.M., P. Dalsgaard, and K. Halskov, "Creativity methods in interaction design.", DESIRE 10, 2010, pp. 12-21.

[43] Onarheim, B., and S. Wiltschnig, "Opening and constraining: constraints and their role in creative processes", Proceedings of the First Conference on Creativity and Innovation in Design (DESIRE 2010), (2010), 83-89.

[44] Butler, A.G., and M.A. Roberto, "When Cognition Interferes with Innovation: Overcoming Cognitive Obstacles to Design Thinking: Design thinking can fail when cognitive obstacles interfere; appropriate cognitive countermeasures can help disarm the traps.", ResearchTechnology Management 61(4), 2018, pp. 45-51.

[45] Kaptelinin, V., and B.A. Nardi, Acting with Technology: Activity Theory and Interaction Design, MIT Press, 2006.

[46] Kaptelinin, V., K. Kuutti, and L. Bannon, “Activity theory: Basic concepts and applications", HumanComputer Interaction, Springer (1995), 189-201. 
[47] Clemmensen, T., V. Kaptelinin, and B. Nardi, "Making HCI theory work: an analysis of the use of activity theory in HCI research", Behaviour \& Information Technology 35(8), 2016, pp. 608-627.

[48] Vygotskiü, L.S., and A. Kozulin, Thought and language, MIT Press, Cambridge, Mass, 1986.

[49] Engestrom, Y., "Activity theory as a framework for analyzing and redesigning work", Ergonomics 43(7), 2000, pp. 960-974.

[50] Engeström, Y., "Activity theory and individual and social transformation", In Perspectives on activity theory. Cambridge University Press, New York, NY, US, 1999, 19-38.

[51] Wiser, F., C. Durst, and N. Wickramasinghe, "Using Activity Theory Successfully in Healthcare: A Systematic Review of the Theory's Key Challenges to Date", 2019, pp. 10 .

[52] große Deters, F., S. Tams, A. Johnston, and J. Thatcher, "Designing Experimental Studies", ICIS 2019 Proceedings, 2019.

[53] Beyhl, T., and H. Giese, "The Design Thinking Methodology at Work: Capturing and Understanding the Interplay of Methods and Techniques", In H. Plattner, C. Meinel and L. Leifer, eds., Design Thinking Research. Springer International Publishing, 2016, 49-65.

[54] Brown, T., "Design thinking", Harvard business review 86(6), 2008, pp. 84.

[55] Vogel, J., J. Schuir, C. Koßmann, O. Thomas, F. Teuteberg, and K.-C. Hamborg, "LET'S DO DESIGN THINKING VIRTUALLY: DESIGN AND EVALUATION OF A VIRTUAL REALITY APPLICATION FOR COLLABORATIVE PROTOTYPING”, ECIS 2021 Research Papers, 2021.

[56] Lattemann, C., D. Siemon, D. Dorawa, and B. Redlich, "Digitization of the Design Thinking Process Solving Problems with Geographically Dispersed Teams", Design, User Experience, and Usability: Theory, Methodology, and Management, Springer International Publishing (2017), 7188 .

[57] Siemon, D., B. Redlich, C. Lattemann, and S. RobraBissantz, "Forming Virtual Teams - Visualization with Digital Whiteboards to Increase Shared Understanding, Satisfaction and Perceived Effectiveness", ICIS 2017 Proceedings, 2017.

[58] Lalsing, V., "People Factors in Agile Software Development and Project Management", International Journal of Software Engineering \& Applications 3(1), 2012, pp. 117-137.

[59] Sørensen, J.K., "Exploring Constrained Creative Communication: The Silent Game as Model for Studying Online Collaboration", International Journal of E-Services and Mobile Applications (IJESMA) 9(4), 2017, pp. 1-23.

[60] Nemeth, C.J., B. Personnaz, M. Personnaz, and J.A. Goncalo, "The liberating role of conflict in group creativity: A study in two countries", European Journal of Social Psychology 34(4), 2004, pp. 365-374.

[61] Goncalo, J.A., J.A. Chatman, M.M. Duguid, and J.A. Kennedy, "Creativity from Constraint? How the Political Correctness Norm Influences Creativity in Mixed-sex Work Groups", Administrative Science Quarterly 60(1), 2015, pp. 1-30.

[62] Camacho, M.L., and P.B. Paulus, "The role of social anxiousness in group brainstorming", Journal of Personality and Social Psychology 68(6), 1995, pp. 10711080.

[63] Norman, D.A., The Design of Everyday Things, Basic Books, Inc., USA, 2002.

[64] Ohly, S., and C. Fritz, "Work characteristics, challenge appraisal, creativity, and proactive behavior: A multi-level study", Journal of Organizational Behavior 31(4), 2010, pp. 543-565.

[65] Mayring, P., "Qualitative content analysis: theoretical foundation, basic procedures and software solution", $p$. 143, Social Science Open Access Repository (SSOAR), 2014.

[66] Boer, N.-I., P.J. van Baalen, and K. Kumar, “An activity theory approach for studreinying the situatedness of knowledge sharing", Proceedings of the 35th Annual Hawaii International Conference on System Sciences, IEEE Comput. Soc (2002), 1483-1492.

[67] Madjar, N., E. Greenberg, and Z. Chen, "Factors for radical creativity, incremental creativity, and routine, noncreative performance.", Journal of Applied Psychology 96(4), 2011, pp. 730-743.

[68] Pilcicki, R., D. Siemon, and C. Lattemann, "How Virtual Teams Collaborate Creatively under Communication Constraints", AMCIS 2021 Proceedings, 2021.

[69] Santos, C.M., S. Uitdewilligen, and A.M. Passos, "Why is Your Team More Creative Than Mine? The Influence of Shared Mental Models on Intra-group Conflict, Team Creativity and Effectiveness", Creativity and Innovation Management 24(4), 2015, pp. 645-658.

[70] Werner, C., Z.S. Li, N. Ernst, and D. Damian, "The Lack of Shared Understanding of Non-Functional Requirements in Continuous Software Engineering: Accidental or Essential?", 2020 IEEE 28th International Requirements Engineering Conference (RE), (2020), 90101. 